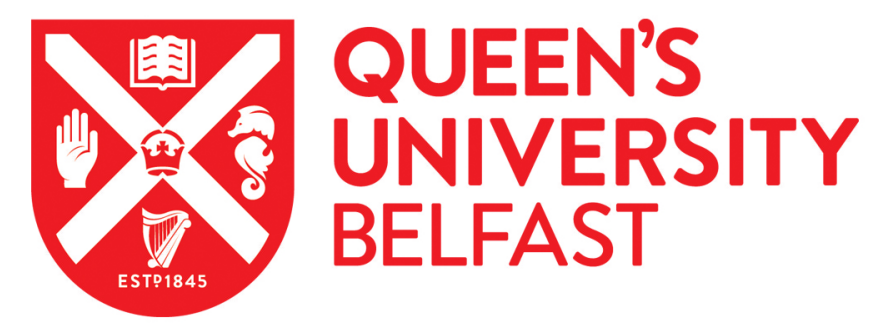

\title{
Battery Energy Storage Systems Allocation Considering Distribution Network Congestion
}

Mohamed, A. A. R., Morrow, D. J., Best, R., Bailie, I., Cupples, A., \& Pollock, J. (2020). Battery Energy Storage Systems Allocation Considering Distribution Network Congestion. In 2020 IEEE PES Innovative Smart Grid Technologies Europe (ISGT-Europe) (pp. 1015). Institute of Electrical and Electronics Engineers Inc.. https://doi.org/10.1109/ISGT-Europe47291.2020.9248982

Published in:

2020 IEEE PES Innovative Smart Grid Technologies Europe (ISGT-Europe)

Document Version:

Peer reviewed version

Queen's University Belfast - Research Portal:

Link to publication record in Queen's University Belfast Research Portal

Publisher rights

Copyright 2020 IEEE. This work is made available online in accordance with the publisher's policies. Please refer to any applicable terms of use of the publisher.

\section{General rights}

Copyright for the publications made accessible via the Queen's University Belfast Research Portal is retained by the author(s) and / or other copyright owners and it is a condition of accessing these publications that users recognise and abide by the legal requirements associated with these rights.

Take down policy

The Research Portal is Queen's institutional repository that provides access to Queen's research output. Every effort has been made to ensure that content in the Research Portal does not infringe any person's rights, or applicable UK laws. If you discover content in the Research Portal that you believe breaches copyright or violates any law, please contact openaccess@qub.ac.uk. 


\section{Battery Energy Storage Systems Allocation Considering Distribution Network Congestion}

\author{
Ahmed A.Raouf Mohamed \\ EPIC Research Cluster \\ Queen's University Belfast \\ Belfast, UK
}

Ian Bailie

NIE Networks

Belfast, UK

\author{
D. John Morrow \\ EPIC Research Cluster \\ Queen's University Belfast \\ Belfast, UK
}

Andrew Cupples

NIE Networks

Belfast, UK
Robert J. Best

EPIC Research Cluster

Queen's University Belfast

Belfast, UK

Jonathan Pollock

ESB Networks

Dublin, Republic of Ireland

\begin{abstract}
This paper proposes an operational planning strategy for battery energy storage systems (BESS) in medium voltage distribution networks. This strategy determines the optimal location and size for BESS as well as the discharging and charging schedules. The objective of this methodology is to improve reliability and stability by relieving distribution network congestion, such as voltage violations and lines overloading. Particle Swarm, Firefly, Novel Bat, Krill herd and Coyote optimization algorithms have been utilized to find the optimal solutions that improve the network's performance by mitigating network stresses. The strategy is implemented and validated using two networks; a 53-node test feeder located in Northern Ireland and the 33-bus radial distribution network. Actual demand measurements were used and high uptake scenarios for low carbon technologies were investigated.
\end{abstract}

Index Terms-Allocation and sizing, battery energy storage system, distribution networks, low carbon technologies (LCTs), optimization, scheduling.

\section{INTRODUCTION}

The pace of the energy evolution is undergoing a global acceleration. People and governments are committing to the transition to carbon-free, low-emission economies to reduce harmful effects on human health and the environment. This decarbonization initiative intensely involved the electrical energy sector. This can be observed from the integration of low carbon technologies (LCTs) in the power network. The most popular LCTs in the power distribution network are; solar photovoltaics (PV), electric vehicles (EV) and heat pumps (HP). Increasing the installations of LCTs in the distribution network (DN) introduces various technical challenges such as voltage violations, reverse power, thermal overloading and power quality issues [1].

Battery energy storage systems (BESS) development and deployment is rising rapidly due to their attractive benefits. BESS is a powerful tool that can be employed to achieve energy arbitrage in the $\mathrm{DN}$ for economic and technical paybacks. However, their integration requires careful planning and management to achieve maximized benefits. Many studies have evaluated the integration of BESS in the DN for different purposes. Finding the optimal size and location of BESS in the $\mathrm{DN}$ is an important planning optimization problem to be settled. Determining the location and size of BESS depends on the objective to be achieved from the BESS. BESS can provide different services which can be formulated into objective functions in the optimization problem. This optimization problem is a nondeterministic polynomial time hard optimization problem

This work is part of SPIRE 2 project (Storage Platform for the Integration of Renewable Energy), supported by the European Union's INTERREG VA Programme (Grant No. IVA5038), managed by the Special EU Programmes Body (SEUPB). The views and opinions expressed in this paper do not necessarily reflect those of the European Commission or the SEUPB. than can be solved using different analytical, mathematical and heuristic/metaheuristics programming algorithms [2].

Different studies proposed various planning approaches based on different programming algorithms and optimization routines to provide applicable solutions to this problem. In [3], the BESS allocation and sizing is presented using nondominated sorting genetic algorithm-II to minimize the losses, improve the voltage and extend the lifespan of the BESS. In [4], the problem was solved along with determining BESS power scheduling to reduce the BESS investment and daily system operation costs as well as enhancing the utilization of wind power using chance-constrained programming and differential evolution algorithm.

Firefly Algorithm (FA) and gravitational search algorithm were used in [5], to determine the optimal BESS size to be installed with PV distributed generation (DG) to mitigate voltage rise. In [6], a two-stage optimal power flow model is presented to determine the BESS location and capacity using genetic algorithm. The model aims to minimize the total net present value of the DN in presence of PV and wind DGs. In addition, the study optimizes BESS charging/discharging dispatch and the depth of discharge to minimize the losses taking into consideration BESS lifetime. In [7], a modified version of Bat Algorithm (BA) is employed to optimally site and size BESS in microgrids to minimize the total cost.

This paper utilizes the integration of BESS to solve network congestions represented in voltage drop and lines overloading due to the high LCTs uptake scenario. The main contributions of this paper can be summarized as follows: 1) proposing an effective strategy that determines the BESS size, locations and power schedules for congestion management which can be used for any type of DGs, 2) exploits the BESS deployment by introducing a powerful objective function for the charging, 3) introducing and testing new optimization algorithms for the BESS allocation problem, 4) finally, an actual distribution network located in Northern Ireland and real recorded measurements were used to validate the proposed strategy.

The paper is organized as follows: Section II presents the proposed strategy with the mathematical formulation and optimization algorithms; Section III introduces the case studies and results and Section VI contains the conclusion.

\section{The StRATEgY}

The aim of this strategy is to enhance network performance by installing and managing BESS to solve network congestions and violations. Enhancing the network performance in this paper is achieved through optimizing the voltage profile by maintaining the voltage at end nodes within the acceptable limits considering different practical technical constraints. Optimizing the voltage profile can be translated into an objective function by maximizing the voltage profile improvement index (VPII) [8]. The VPII 
indicates the improvement achieved on the voltage profile of a DN due to the installation of power sources on the network. The power sources in this paper are BESS. The VPII for a system with $N$ buses at a specific hour can be simplified as:

$$
V P I I_{h}=\frac{\sum_{i=1}^{N} V_{i, h}^{a}}{\sum_{i=1}^{N} V_{i, h}^{b}}
$$

$V_{i, h}^{a} \quad$ Voltage at node $i$ after installing the BESS.

$V_{i, h}^{b} \quad$ Voltage at node $i$ before installing the BESS.

$h \quad$ Index of hours.

This paper focuses on the undervoltage violation that may occur in the winter due to the rapid deployment of EVs and HPs. In order to simulate these scenarios, the maximum load profile is considered in this work as the BESS should be sized based on the worst-case scenario. Hence, the optimization will aim to maximize the VPII by optimally discharging the BESS. However, the same strategy can be applied to other congestion scenarios (e.g. overvoltage issues from PV overgeneration) by minimizing the VPII through optimally charging the BESS or controlling the inverter reactive power efficiently. The proposed strategy assumes that the BESS inverter is operating on a unity power factor and only the active power can be controlled, the strategy consists of three main stages: BESS Location, BESS Discharge Schedule and Sizing, and BESS Charging Schedule.

\section{A. BESS Location}

In order to determine the BESS location, the algorithm conducts power flow analysis for 24-hours using backward/forward sweep method [9]. The results obtained from this power flow method was validated using the NEPLAN AG power system software. Then, it determines the hours that have congestions in terms of voltage and line violations. The highly congested hour, which has the worst violations is selected for determining the location of the BESS. At this hour, the optimization algorithm initializes two sets of variables based on the number of BESS; the first set represents the locations and the second set denotes the BESS power that can be injected from these locations to solve network congestion by minimizing the inverse of the VPII as:

$$
\begin{gathered}
\min \left(1 / V P I I_{h}\right) \quad \text { s.t. } \quad l_{b} \leq x \leq u_{b} \\
1 \leq x \leq N \quad \text { for location variables } \\
0 \leq x \leq P_{d i}^{\max } \quad \mid \quad x \in\left[P_{n, h}^{d i}\right]
\end{gathered}
$$

Where $l_{b}$ and $u_{b}$ represent the lower and upper bounds of the optimization algorithm respectively. The BESS number is symbolized by $n$, and $P_{n}^{d i}$ is the BESS discharging power. $P_{d i}^{\max }$ is the maximum discharging BESS power which is determined for a network using the difference between the peak demand value in the maximum load profile case $\left(P_{d e}^{p \cdot \max }\right)$ and the peak demand value in the base case $\left(P_{d e}^{\text {p.base }}\right)$ expressed as:

$$
P_{d i}^{\max }=P_{d e}^{p \cdot \max }-P_{d e}^{p . b a s e}
$$

These sets of variables (locations and power injections) are initialized by the optimization algorithm for a power flow calculation at the congested hour. The optimization algorithm keeps updating the solution variables until optimal solutions are found which represent the optimal sites of BESS to solve network congestion with minimum power injections. The minimum power injections are defined as the power that should be injected from the BESS node to regulate the minimum nodal voltage to its lower threshold value without violating the rating of the lines. The obtained BESS locations are also validated by determining the voltage stability index (VSI) [10], at each node during the maximum load profile. The nodes that have lower values of VSI are the most suitable nodes for BESS placement.

\section{B. BESS Discharging Schedule and BESS Size}

After determining the BESS locations, this step establishes the optimal minimal BESS active power injections at each congested hour that solves the congestion. The proposed scheduling strategy employs optimization algorithm to develop solutions of the BESS power dispatch at each hour constrained by Eq. (4). These values are entered to a power flow routine for each congested hour. After each power flow, the algorithm evaluates the objective function Eq. (2) at each hour, and the optimization algorithm updates these solutions and keeps running the power flow until optimal solutions are found. The solutions obtained represent the minimal BESS power injections in MW to solve the network congestions. These values are then used to determine the total BESS capacity $\left(B E S S^{c}\right)$ in MWh as:

$$
B E S S_{n}^{c}=\sum_{h=1}^{T_{d}} P_{h}^{d i} \tau
$$

Where $T_{d}$ is the total number of congested hours, and $\tau$ is the data resolution value ( 1 for 1 -hour resolution, 0.5 for 30 minutes resolution).

\section{BESS Charging Schedule}

This paper focuses on solving network challenges represented mainly in undervoltage violations and overloading lines which can be achieved by optimally placing, sizing, and discharging the BESS. However, the work is extended to achieve maximum BESS utilization by charging it wisely through introducing an objective function for valley filling. Load valley filling aims to shift the demand in the off-peak periods to reduce the stresses on the electrical network as well as reducing energy costs. This is essential in the areas where the PV generation is very high, and the load curve resembles the duck shape as observed in California [11]. Filling valleys can be achieved by determining the optimal power values that should be consumed at each hour in order to flatten the valleys. This can be mathematically formulated as a function that minimizes the difference between the load curve power points expressed for a period that starts at $h_{o}$ and ends at $h_{f}$ for $k$ hours as:

$$
\begin{array}{r}
\min \left(\frac{P_{\max }}{P_{a v g}}+\frac{P_{\text {max }}+P_{a v g}}{P_{\text {min }}}+\sqrt{\frac{1}{k} \sum_{h=h_{o}}^{h_{f}}\left|P_{h}-P_{a v g}\right|^{2}}\right)(7) \\
P_{h}=\sum_{n=1}^{z} P_{n, h}^{c h}+P_{h}^{\text {demand }}+P_{h}^{\text {losses }}-\sum_{i=1}^{m} P_{i, h}^{D G}(8)
\end{array}
$$

$P_{\max } \quad$ Maximum grid power within the selected period. $P_{\text {min }} \quad$ Minimum grid power within the selected period. $P_{a v g} \quad$ Mean value of grid power for the selected period.

$P_{h} \quad$ Grid power at specific hour.

$P_{n}^{c h} \quad$ BESS charging power.

$P$ losses Line power losses.

$P_{i, h}^{D G} \quad$ DG power injection at specific hour.

$m \quad$ Number of DGs.

$z \quad$ Number of BESS.

The algorithm distributes the BESS charging power to fill the demand valleys and flatten the load to improve system efficiency, stability and reliability. Additionally, this methodology can be used to determine the amount of power to be managed for demand side management programs and 
pumped storage scheduling. The optimal solutions (BESS charging power) are constrained by the rate of charge $(R o C)$, the $R o C$ is taken as $25 \%$ of BESS capacity to prolong the BESS life and assure safe operation.

$$
0 \leq x \leq R o C \quad \mid \quad x \in\left[P_{n, h}^{c h}\right]
$$

The previous stages are performed sequentially considering the network and BESS technical constraints. The network active and reactive power balances are satisfied within the power flow routine itself. The charging and discharging power limits are satisfied by the optimization algorithm using the upper and lower bounds Eq. (4) and Eq. (9). The following equality and inequality constraints are fully satisfied within the strategy routine by converting the constrained problem to an unconstrained optimization problem using the penalty function method.

1) Voltage limits: The voltage at $i^{\text {th }}$ node should not exceed its permissible limits ( $0.95-1.05$ p.u.). In the UK, the acceptable voltage limits for the $11 \mathrm{kV}$ network as defined in ESQCR (No. 2665) are $\pm 6 \%$ of the nominal voltage. In this work, voltage tolerance limits of $\pm 5 \%$ are used as per the US standard ANSI C84.1. Many network operators do, however, prefer to specify tighter voltage limits based on the working practice to mitigate voltage variations.

$$
V_{\min } \leq V_{i} \leq V_{\max } \quad \forall \quad i \in 1,2, \ldots, N
$$

2) Line Flow: The current flows in $m^{\text {th }}$ line should not surpass the predefined maximum current rating.

$$
I_{m} \leq I_{m}^{\max } \quad \forall \quad m \in 1,2, \ldots, N-1
$$

3) State of Charge (SoC): The BESS power should be preserved within the $S o C$ limits $(10 \%$ to $90 \%)$ to increase its lifespan.

$$
S o C_{\min } \leq S o C_{B E S S} \leq S o C_{\max }
$$

4) BESS Capacity: The total discharged/charged power over time from any BESS cannot exceed its capacity.

$$
\sum^{T} P_{h}^{B E S S} \tau \leq B E S S_{n}^{c} \quad \mid \quad P_{h}^{B E S S} \in\left[P_{n, h}^{d i}, P_{n, h}^{c h}\right]
$$

The optimization problems in this paper can be divided into three parts; finding the optimal BESS locations, determining the discharging schedules and BESS sizes, and calculating the BESS charging schedule. Different types of algorithms can be used to solve these optimization problems. In this paper, global optimization nature-based metaheuristic algorithms are used to solve these optimization problems due to their efficacy in solving extensive complex engineering problems [12]. These algorithms are inspired by natural phenomena and biological behaviors of animals.

Five algorithms were selected to examine their capabilities in providing solutions. For the purpose of a fair comparison between these algorithms, all these algorithms are classified as swarm intelligent optimization algorithms. Particle swarm optimization (PSO) [13], and Firefly Algorithm (FA) [14], are used due to their competence in applications related to the field of electrical engineering and power systems. Whilst, Novel Bat Algorithm (NBA) [15], Krill Herd (KH) algorithm [16], and Coyote Optimization Algorithm (COA) [17], have not been used widely in that field, but they were considered to examine their abilities in solving these types of problems.

\section{CASE Studies AND Results}

To validate the proposed strategy, a load profile has been generated using actual measurements for a distribution network located in Northern Ireland from December 2016, which is representative of the winter demand pattern in the UK. To investigate the network congestion due to high future uptake level of LCTs, a 50\% use of HPs was assumed, which would increase the maximum demand by $12.5 \%$ [18]. In addition, an average charging pattern of $200 \mathrm{EV}$ was considered and modelled on the average EV daily charging pattern of Northern Ireland. LCTs patterns and scenarios were produced based on an official report on the future of Northern Ireland networks [19]. The generated demand profile is the worst-case demand profile scenario of this distribution network. The proposed strategy is implemented for three installation cases; one BESS, two BESS and three BESS for two different radial distribution networks.

\section{A. 53-node test feeder}

The first test system is a $11 \mathrm{kV}$ feeder of 53 nodes located in Northern Ireland. A PV DG of 0.7 MW is located on node 13. The generated load profile was applied to this system, Fig. 1 shows the test feeder and the violated nodes and lines. Six hours have voltage or line violations from 16:00 hr to 21:00 hr. The minimum voltage is 0.934 p.u. at bus 53 during 18:00 hr. As shown in Fig. 2 and Fig. 3, the high uptake of LCTs caused severe violations affecting the system stability, security and power quality. The proposed algorithm solves these violations by integrating and utilizing the BESS in the $\mathrm{DN}$. As shown in the same figures, the capability of the BESS to solve these violations has been illustrated by allocating BESS as given in Table I.

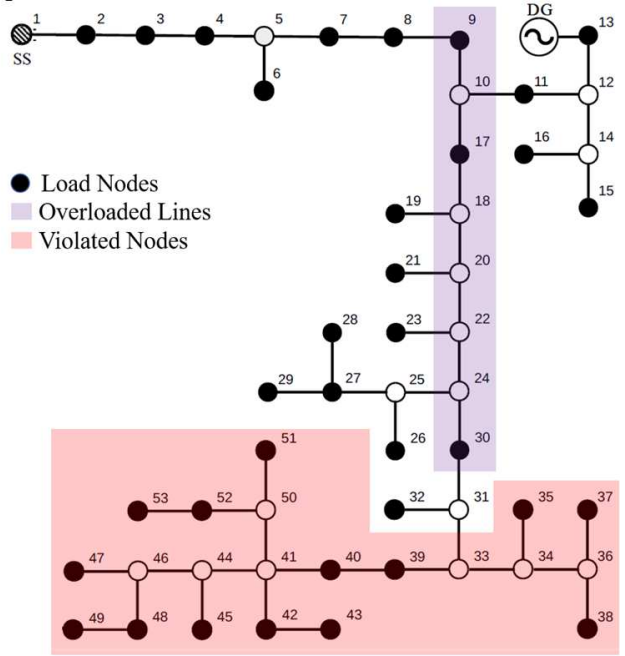

Fig. 1. 53-node test feeder with violated nodes and lines

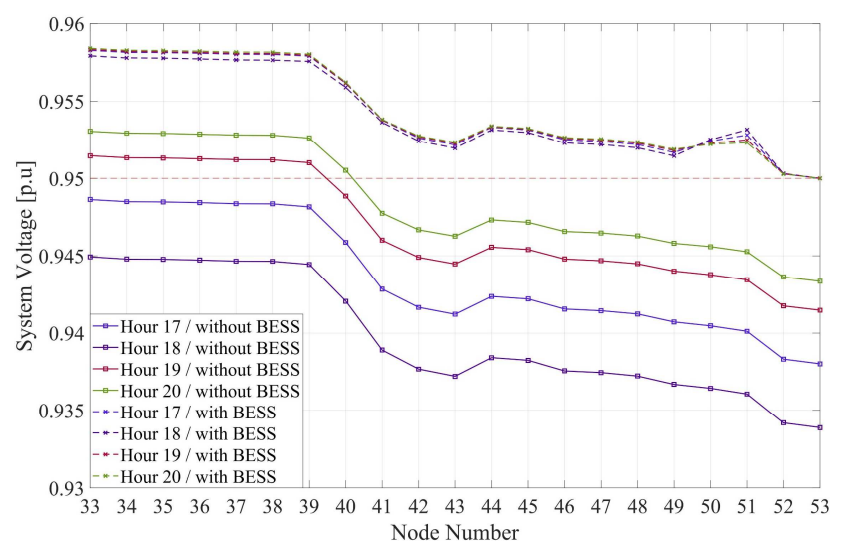

Fig. 2. Node voltage before and after the installation of BESS (Severest violations from 17:00 $\mathrm{hr}$ to $20: 00 \mathrm{hr}-53$ node system)

The results in Table I, are the minimum BESS sizes to solve the violations plus a $20 \%$ factor denoting the $S o C$. In 
this paper, the minimum value of $S o C$ is taken as $10 \%$, however, it can be set to $30-50 \%$ to avoid damaging the BESS by excessive discharge. All the optimization methods obtained good results. Though, PSO obtained the best values.

TABLE I

BESS ALLOCATION AND SIZING RESUlts - 53-Node TeSt FEEDER

\begin{tabular}{|c|c|c|c|c|}
\hline Case & $\begin{array}{c}\text { Optimization } \\
\text { Algorithm }\end{array}$ & $\begin{array}{c}\text { Optimal } \\
\text { Location } \\
\text { Bus }\end{array}$ & $\begin{array}{c}\text { Optimal } \\
\text { Size } \\
{[\mathrm{MWh}]}\end{array}$ & $\begin{array}{c}\text { Total BESS } \\
\text { size } \\
{[\mathrm{MWh}]}\end{array}$ \\
\hline \multirow{5}{*}{$\begin{array}{c}\text { Case I } \\
\text { One } \\
\text { BESS }\end{array}$} & FA & 53 & 2.243 & 2.243 \\
\hline & PSO & 53 & 2.24 & 2.24 \\
\hline & NBA & 46 & 2.463 & 2.463 \\
\hline & $\mathrm{KH}$ & 53 & 2.369 & 2.369 \\
\hline & $\mathrm{COA}$ & 50 & 2.361 & 2.361 \\
\hline \multirow{10}{*}{$\begin{array}{c}\text { Case II } \\
\text { Two } \\
\text { BESS }\end{array}$} & \multirow{2}{*}{ FA } & 49 & 0.711 & \multirow{2}{*}{2.265} \\
\hline & & 53 & 1.554 & \\
\hline & \multirow{2}{*}{ PSO } & 49 & 0.444 & \multirow{2}{*}{2.244} \\
\hline & & 53 & 1.8 & \\
\hline & \multirow{2}{*}{ NBA } & 48 & 0.665 & \multirow{2}{*}{2.333} \\
\hline & & 52 & 1.668 & \\
\hline & \multirow{2}{*}{$\mathrm{KH}$} & 34 & 0.881 & \multirow{2}{*}{2.867} \\
\hline & & 40 & 1.986 & \\
\hline & \multirow{2}{*}{$\mathrm{COA}$} & 52 & 0.984 & \multirow{2}{*}{2.645} \\
\hline & & 53 & 1.661 & \\
\hline \multirow{15}{*}{$\begin{array}{c}\text { Case III } \\
\text { Three } \\
\text { BESS }\end{array}$} & \multirow{3}{*}{ FA } & 43 & 0.525 & \multirow{3}{*}{2.485} \\
\hline & & 47 & 1.37 & \\
\hline & & 49 & 0.59 & \\
\hline & \multirow{3}{*}{ PSO } & 47 & 0.225 & \multirow{3}{*}{2.293} \\
\hline & & 49 & 0.568 & \\
\hline & & 53 & 1.5 & \\
\hline & \multirow{3}{*}{ NBA } & 47 & 0.418 & \multirow{3}{*}{2.39} \\
\hline & & 49 & 0.408 & \\
\hline & & 53 & 1.564 & \\
\hline & \multirow{3}{*}{$\mathrm{KH}$} & 33 & 1.438 & \multirow{3}{*}{3.286} \\
\hline & & 35 & 0.879 & \\
\hline & & 44 & 0.969 & \\
\hline & \multirow{3}{*}{$\mathrm{COA}$} & 26 & 0.801 & \multirow{3}{*}{3.553} \\
\hline & & 36 & 1.135 & \\
\hline & & 46 & 1.617 & \\
\hline
\end{tabular}

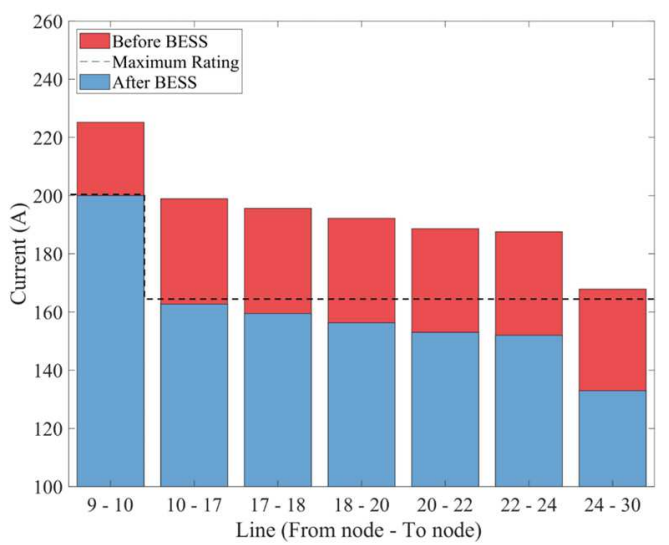

Fig. 3. Violated lines before and after the intrusion of BESS at 18:00 hr

Regarding the BESS charging and load flattening, the case study in this paper is the winter demand. Thus, there is no reverse power flow or over voltage violation risk. Hence, the objective of the charging in this case is to reduce the charging cost. This can be achieved by implementing the charging process during the low-price electricity rate period (e.g. 1 am to $8 \mathrm{am}$ ). The optimal BESS charging/discharging schedule for the three cases obtained by PSO is presented in Table II. Fig. 4 shows the grid power before and after BESS charging/discharging scheduling of the three cases using PSO. As shown in Fig. 4, the proposed algorithm managed to solve the network issues by optimally dispatch the BESS power. During the discharging mode, the BESS provided the required support to the network to solve all the infringements. While, during the charging mode, the BESS charges at the lowest rate and flatten the demand.
TABLE II

BEST CHARGING/DISCHARGING SCHEDULE USING PSO 53-NODE TEST FEEDER

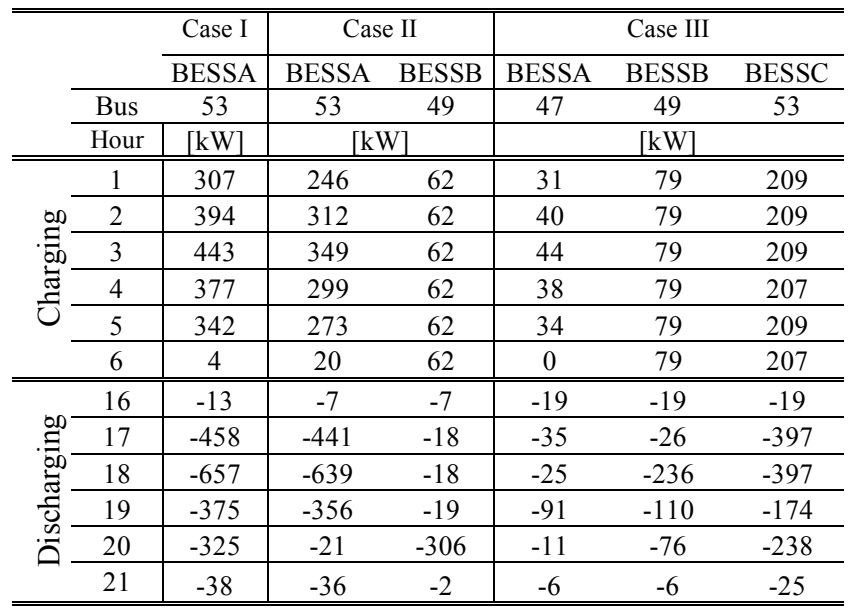

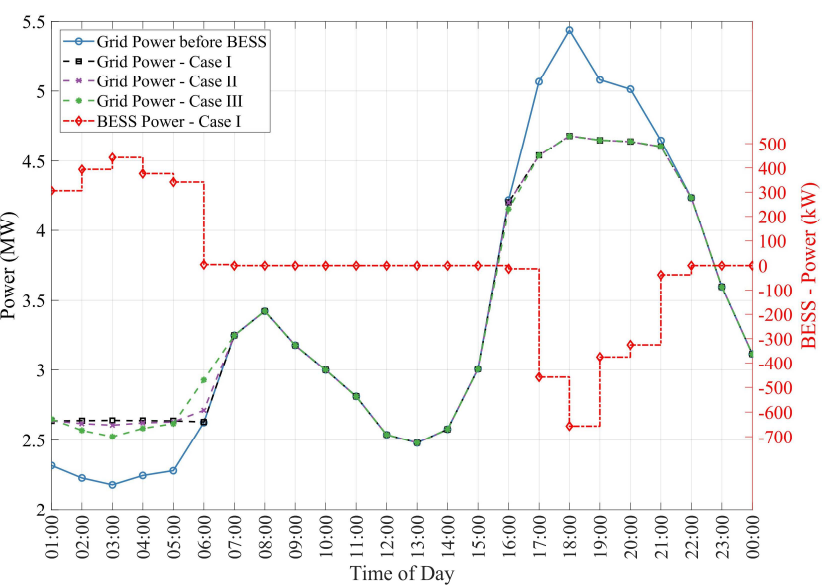

Fig. 4. Grid power before and after the BESS installation cases - PSO

\section{B. 33-bus distribution system}

To demonstrate the effectiveness of the proposed strategy, it has also been applied to the $12.66 \mathrm{kV} 33$-bus radial distribution network [20]. The same load profile was modelled on the network. Voltage violations occurred during the peak period and the minimum voltage is $0.932 \mathrm{p} . \mathrm{u}$. at bus 18 for 18:00 hr. The best BESS allocation and sizing results obtained among all the algorithms are tabulated in Table III, and the voltage profile for the violated nodes before and after installing the BESS is shown in Fig. 5.

TABLE III

BESS ALLOCATION AND SIZING RESULTS - 33-BUS NETWORK

\begin{tabular}{ccccc}
\hline \hline Case & $\begin{array}{c}\text { Optimization } \\
\text { Algorithm }\end{array}$ & $\begin{array}{c}\text { Location } \\
\text { Bus }\end{array}$ & $\begin{array}{c}\text { Size } \\
{[\mathrm{MWh}]}\end{array}$ & $\begin{array}{c}\text { Total size } \\
{[\mathrm{MWh}]}\end{array}$ \\
\hline Case I & FA & 16 & 1.778 & 1.778 \\
\hline \multirow{2}{*}{ Case II } & NBA & 17 & 0.828 & \multirow{2}{*}{1.265} \\
\cline { 3 - 4 } Case III & \multirow{2}{*}{ NBA } & 32 & 0.437 & \multirow{2}{*}{1.276} \\
\cline { 3 - 4 } & & 16 & 0.387 & \\
\cline { 3 - 4 } & & 33 & 0.49 & \\
\hline \hline
\end{tabular}

\section{Discussion}

The proposed strategy offered different BESS allocation and scheduling options to relieve network's stresses. In all cases, the losses were optimized, the best loss minimization was obtained using three BESS. Alternatively, the proposed strategy can be used for different DG types. For the 53-node system, and from the discharging part in Table II, a $657 \mathrm{~kW}$ DG can be placed on bus 53 to solve the network issues with the same power injections schedule. 


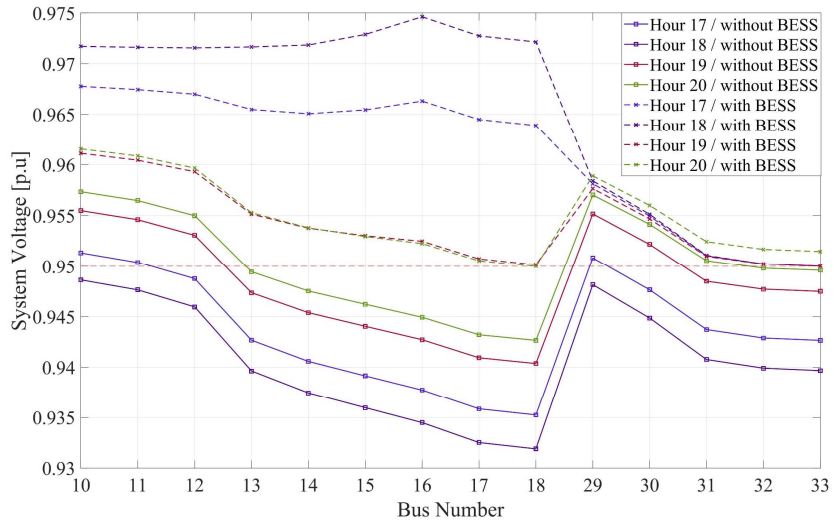

Fig. 5. Node voltage before and after the installation of BESS

(Severest violations from 17:00 hr to 20:00 hr - 33 bus system)

The swarm-inspired algorithms proved their capabilities in solving the proposed strategy. For the two test systems, PSO, FA and NBA obtained good results for the three cases. Nevertheless, $\mathrm{KH}$ and COA obtained satisfactory results only in case I. The parameters of each algorithm were kept default, as these parameters can be considered as an optimization problem. However, different numbers of particles/candidates were tested, and the number of iterations was varied until good results were obtained. In addition, for each case, the simulations were repeated 10 times for each optimization algorithm to ensure that the obtained results were consistent. The processing time is an important factor that should be considered in selecting the appropriate optimization algorithm. However, in the planning approaches, the simulation time is not a crucial issue. Conversely, this time is important in the approaches that require online and fast actions. Hence, the processing time of the implemented optimization algorithms can be ranked respectively from fastest to slowest as; PSO, FA, NBA, KH and COA.

Selecting the best option from these installation scenarios is left to the network planners and operators, according to other practical aspects such as the applicability of installing BESS in certain locations, capacity, and cost restrictions. Undoubtedly, the debate about the BESS investment profitability is still ongoing. However, with the ongoing trend towards the net zero targets, new markets and schemes have been introduced that involve different type of ancillary services from the distributed resources (e.g. DS3 services in the island of Ireland). In these schemes, the BESS has a great opportunity to increase its profitability by providing the network with the fast response services as well as energy arbitrage. The BESS investment costs and expected revenues in the UK and Ireland are quantified in [21].

\section{CONCLUSION}

This paper proposed an operational planning strategy to determine the optimal locations, sizes and discharge/charge schedules of BESS in MV networks to mitigate problems that could arise from the rapid deployment of LCTs. The strategy considered minimizing the installation cost by determining the minimum BESS size that solves the network stresses. New metaheuristic algorithms were tested for the first time in providing solutions to BESS allocation and scheduling, including NBA, KH, and COA. The NBA obtained promising results among these algorithms. Moreover, COA and $\mathrm{KH}$ did not outperform any of other metaheuristic algorithms in solving this global optimization problem. Thus, it is highly recommended to rely on robust algorithms such as PSO, FA and NBA in solving this type of problem. Simulations performed on two different radial networks for single and multiple BESS installation scenarios proved the effectiveness of the proposed strategy. The strategy model can be modified to accommodate a wider range of constraints and objectives to meet the specific requirements of BESS owners. For future research, the proposed strategy can be applied to large complex systems to investigate its scalability as well as studying other congestion scenarios such as overvoltage issues due to PV generation.

\section{REFERENCES}

[1] A. Navarro-Espinosa and L. F. Ochoa, "Probabilistic Impact Assessment of Low Carbon Technologies in LV Distribution Systems," in IEEE Transactions on Power Systems, vol. 31, no. 3, pp. 2192-2203, May 2016.

[2] M. Zidar, P. S. Georgilakis, N. D. Hatziargyriou, T. Capuder and D. Škrlec, "Review of energy storage allocation in power distribution networks: applications, methods and future research," in IET Generation, Transmission \& Distribution, vol. 10, no. 3, pp. 645-652, 2016.

[3] K. Khalid Mehmood, S. U. Khan, S. Lee, Z. M. Haider, M. K. Rafique and C. Kim, "Optimal sizing and allocation of battery energy storage systems with wind and solar power DGs in a distribution network for voltage regulation considering the lifespan of batteries," in IET Renewable Power Generation, vol. 11, no. 10, pp. 1305-1315, 2017.

[4] Y. Zhang, Z. Y. Dong, F. Luo, Y. Zheng, K. Meng and K. P. Wong, "Optimal allocation of battery energy storage systems in distribution networks with high wind power penetration," in IET Renewable Power Generation, vol. 10, no. 8, pp. 1105-1113, 2016.

[5] L. A. Wong, H. Shareef, A. Mohamed, and A. A. Ibrahim, "Optimal Battery Sizing in Photovoltaic Based Distributed Generation Using Enhanced Opposition-Based Firefly Algorithm for Voltage Rise Mitigation," The Scientific World Journal, vol. 2014, pp. 1-11, 2014.

[6] J. Xiao, Z. Zhang, L. Bai and H. Liang, "Determination of the optimal installation site and capacity of battery energy storage system in distribution network integrated with distributed generation," in IET Generation, Transmission \& Distribution, vol. 10, no. 3, pp. 601-607, 2016.

[7] B. Bahmani-Firouzi and R. Azizipanah-Abarghooee, "Optimal sizing of battery energy storage for micro-grid operation management using a new improved bat algorithm,” Int. J. Elect. Power, vol. 56, pp. 42-54, 2014.

[8] P.Chiradeja and R.Ramakumar, "An approach to quantify the technical benefits of distributed generation," IEEE Transactions on Energy Conversion, vol. 19, no. 4, pp. 764-773, Dec. 2004.

[9] D. Shirmohammadi, H. W. Hong, A. Semlyen and G. X. Luo, "A compensation-based power flow method for weakly meshed distribution and transmission networks," in IEEE Transactions on Power Systems, vol. 3, no. 2, pp. 753-762, May 1988.

[10] G. A. Mahmoud, "Voltage stability analysis of radial distribution networks using catastrophe theory," in IET Generation, Transmission \& Distribution, vol. 6, no. 7, pp. 612-618, July 2012.

[11] P. Denholm, M. O'Connell, G. Brinkman, and J. Jorgenson, "Overgeneration from Solar Energy in California: A Field Guide to the Duck Chart," 2015.

[12] Bozorg-Haddad, Omid, Mohammad Solgi, and Hugo A. Loaiciga. Metaheuristic and evolutionary algorithms for engineering optimization. vol. 294. John Wiley \& Sons, 2017.

[13] Eberhart, R. C. and Kennedy, J. A new optimizer using particle swarm theory. Proceedings of the sixth international symposium on micro machine and human science. IEEE service center, Piscataway,NJ, Nagoya, Japan, pp. 39-43, 1995.

[14] X.-S.Yang, "Firefly algorithms for multimodal optimization," Stochastic Algorithms: Foundation and Applications SAGA 2009, pp.169-178, 2009.

[15] Meng, X.B., Gao, X.Z., Liu, Y. and Zhang, H., "A novel bat algorithm with habitat selection and Doppler effect in echoes for optimization", Expert Systems with Applications, vol.42, pp. 6350-6364, 2015.

[16] Gandomi, A.H. and Alavi, A.H., 2012. Krill herd: a new bio-inspired optimization algorithm. Communications in nonlinear science and numerical simulation, vol.17(12), pp.4831-4845, 2012

[17] J. Pierezan and L. Dos Santos Coelho, "Coyote Optimization Algorithm: A New Metaheuristic for Global Optimization Problems," 2018 IEEE Congress on Evolutionary Computation (CEC), pp. 1-8, 2018.

[18] Fawcett, Tina, Russell Layberry, and Nick Eyre. "Electrification of heating: the role of heat pumps." BIEE Conference Oxford. 2014.

[19] EA Technology, "Development of the Transform Model for Northern Ireland", June. $2016 . \quad$ [Online]. Available: https://www.nienetworks.co.uk/getmedia/e4547f2d-ee5f-40ac-b9709ea2ed6d0dad/Development-of-the-Transform-Model-for-NIENetworks-v3 1.aspx

[20] M. E. Baran and F. F. Wu, "Network reconfiguration in distribution systems for loss reduction and load balancing," in IEEE Transactions on Power Delivery, vol. 4, no. 2, pp. 1401-1407, April 1989.

[21] Brogan, P., Best, R., Morrow, D., Duncan, R., \& Kubik, M. L, "Stacking Battery Energy Storage Revenues with Enhanced Service Provision". IET Smart Grid, Sept 2019. 